\title{
Yo tan vieja, ¿ya qué? Relaciones sexoafectivas de lesbianas adultas mayores de Bogotá-Colombia ${ }^{1}$
}

\author{
Ana Margarita Fernández de Castro Peñaranda \\ iD https://orcid.org/0000-0002-6338-9039 \\ Facultad Latinoamericana de Ciencias Sociales - FLACSO Sede Ecuador \\ anamargaritafdezdecastro@gmail.com
}

\section{RESUMEN}

Este artículo analiza la construcción de los vínculos sexoafectivos de lesbianas adultas mayores de Bogotá. En consonancia con los planteamientos de la gerontología feminista y del curso de vida, en esta investigación recopilé las historias de vida de ocho lesbianas mayores de sesenta años para comprender cómo sus trayectorias vitales inciden en la manera en que construyen su vida sexo-afectiva en la vejez. A partir del trabajo de campo, evidencié que el género y la sexualidad ejercen gran influencia en las experiencias de envejecimiento de este segmento poblacional, dando lugar a vejeces diferenciales. Asimismo, sostengo que la gestión de las relaciones sexo-afectivas en la vejez y los significados e importancia atribuidos a estas dependen, entre otros, de sus cursos de vida, de sus situaciones materiales actuales, del grado de cercanía con sus familias, de sus expectativas vitales y de la percepción que tienen acerca de sí mismas. Además, están influidos por factores externos como, por ejemplo, la censura hacia su sexualidad y la falta de espacios de lesbosocialización pensados para adultas mayores. Entre dichos significados e importancia, resalto la posibilidad de disponer de compañía, afectos y cuidados, de conseguir el sustento diario y de dar continuidad a su sexualidad.

Este artículo resume algunos hallazgos de mi tesis de maestría en Investigación en Ciencias Sociales con mención en Género y Desarrollo en la Facultad Latinoamericana de Ciencias Sociales - FLACSO Sede Ecuador. 
Palabras clave: lesbianas, vejez, curso de vida, gerontología feminista, relaciones sexoafectivas.

\title{
So old myself, what then? Affective-sexual relationships of older lesbians of Bogota-Colombia
}

\author{
ABSTRACT
}

This article analyzes the construction of the sex-affective relationships of older lesbians in Bogotá. Following the approaches of feminist gerontology and the life course, in this research I compiled the life stories of eight lesbians over sixty. This, to understand how their life trajectories affect the way they build their sex-affective life in old age. From the field work, I identify that gender and sexuality shape aging experiences of this segment. I argue that the building of sex-affective relationships and the meanings and importance attributed depend, among others, of their life courses, their current material situation, the degree of closeness to their families, their life expectations and self-perception. In addition, they are influenced by external factors such as, for example: censorship of their sexuality and the lack of spaces for lesbo-socialization designed for older women. Among these meanings and importance, I expose: the possibility of having company, affection and care, of obtaining daily sustenance and of giving continuity to their sexuality.

Keywords: lesbian, old age, life course, feminist gerontology, affective-sexual relationships. 


\section{INTRODUCCIÓN}

Desde las últimas décadas del siglo XX hemos sido testigos de avances significativos en el reconocimiento de los derechos de las lesbianas. Pese a ello, en esta lucha contra la discriminación se exhibe cierta «ceguera» respecto al edadismo ${ }^{2}$ que afecta a un creciente grupo de lesbianas mayores de sesenta años. De acuerdo con Gracia (2011), la visibilidad que han logrado las lesbianas jóvenes se contrapone con el olvido de las lesbianas adultas mayores incluso en las mismas agendas de las colectivas lésbicas, de tal manera que poco o nada se conoce sobre quiénes son las lesbianas adultas mayores, sobre sus experiencias de envejecimiento, y menos aún, dónde están (Gimeno, 2004). Así pues, sus realidades pasan desapercibidas y, por ende, sus problemáticas tienden a ser ignoradas. Esta «omisión» acarrea un alto costo en las vidas de estas mujeres.

Quizá las problemáticas de las lesbianas adultas mayores estén recogidas dentro de las políticas públicas encaminadas a la protección de la población adulta mayor. Sin embargo, en esos discursos universalistas de que todos y todas somos iguales se ignora que en realidad no lo somos (Rebellato, Azevedo, Miguel y Da Silva, 2021). En efecto, hay una multiplicidad de dimensiones de desigualdad y de opresión que se entrecruzan a lo largo de las trayectorias de vida de las personas, y que van dando lugar a tipos de vejeces diferenciales (Rada Schultze, 2016).

La práctica y la teoría gerontológica convencional ha estado dominada por perspectivas androcéntricas y heterosexistas (Henning, 2017). Por un lado, se ha tendido a analizar la vejez de manera homogénea (basándose en la experiencia de los hombres), ignorando que las experiencias de envejecimiento entre hombres y mujeres son distintas (Freixas, 1997). Por otro lado, se asume que las personas adultas mayores son necesariamente heterosexuales (Gracia, 2011). Estas presunciones contribuyen a la invisibilización de una multiplicidad de experiencias de

2 Discriminación por razón de edad. 
envejecimiento y vejez que no encajan en estas perspectivas sesgadas, como por ejemplo las de las lesbianas.

De acuerdo con Henning (2017), los modelos de los que dispone la gerontología social tradicional para el abordaje de la vejez resultan insuficientes para analizar las experiencias de envejecimiento de la población LGBT. Esto, en la medida en que ignoran el impacto que tienen las dimensiones de género y sexualidad en el curso de vida de las personas y la forma en que dichas dimensiones dan lugar a vejeces diferenciales (Rada Shultze, 2018). Recientemente han surgido teorías críticas - como la gerontología feminista y el curso de vida — que cuestionan los «conceptos más preciados» (Hooyman, Browne, Ray y Richardson, 2002) del quehacer gerontológico planteando nuevas preguntas en torno a la vejez.

Durante las décadas recientes se ha observado un paulatino surgimiento de investigaciones que han procurado abordar el envejecimiento LGBT (Henning y Debert, 2015). No obstante, en esta incipiente literatura, las lesbianas adultas mayores han estado subrepresentadas, a diferencia de los gays, cuyas narrativas han sido privilegiadas en las investigaciones sobre el tema (Raphael y Cruikshank, 2015). Esta situación no ha sido casual, sino que responde, en gran medida, a la mayor invisibilización que experimentan las lesbianas adultas mayores respecto a los gays adultos mayores (Westwood, 2013).

La escasa literatura existente sobre lesbianas adultas mayores se ha concentrado en el Reino Unido (Heaphy, 2009; Westwood, 2013; Traies, 2015; Wilkens, 2015), Estados Unidos (Kehoe, 1989; Garnets y Peplau, 2006; Eversmeyer y Purcell, 2009; Eversmeyer y Purcell, 2012; Woody, 2014; Drumm, 2015; Woody, 2015; Baker, 2016; Averett, Pylant, Craft y Ricks, 2018) y España (Gimeno, 2004; Albarracín, 2008; Gracia, 2011; Albarracín, 2012; García, 2015). En Latinoamérica se evidencian algunas investigaciones en Brasil (Alves, 2010; Lacombe, 2016; Lima, 2020; Lima y Ferreira, 2021), Argentina (Figari y Gemetro, 2009; Rada Schultze, 2018) Perú (Tirado, 2018), Chile (Parra, 2007) y Colombia (Fernández de Castro, 2021). La mayoría de estos estudios se enfocan en comprender cómo las lesbianas que hoy son adultas mayores construyeron sus identidades en contextos represivos y cómo gestionaron sus vínculos sexo-afectivos durante su juventud y adultez; solo unos cuantos se interesan en analizar sus realidades actuales desde un enfoque del curso de vida. De igual modo, gran parte de estos estudios realizan análisis comparativos entre gays y lesbianas, o entre lesbianas y mujeres heterosexuales, pero pocos se centran en abordar exclusivamente la vejez lésbica.

En Bogotá, en el ámbito institucional se han venido elaborando estudios sobre la situación de derechos de las personas LGBT en envejecimiento y vejez con el 
fin de generar recomendaciones para la creación de una política pública enfocada en este segmento poblacional (Secretaría Distrital de Integración Social, 2019; Secretaría Distrital de Planeación, 2019). No obstante, no existen investigaciones que se centren en comprender las realidades que atraviesan las lesbianas adultas mayores de esta ciudad ni sus experiencias de envejecimiento.

Es necesario resaltar que quienes trabajamos sobre este tema nos enfrentamos a la falta de datos cualitativos y cuantitativos sobre lesbianas adultas mayores (Albarracín, 2012; Westwood, 2013, Traies, 2015). En efecto, no se dispone de información precisa sobre el número de lesbianas adultas mayores. En el caso de Bogotá, según la Secretaría Distrital de Planeación (2019), habitan alrededor de 2141 mujeres mayores de 59 años que se autoidentifican como lesbianas, de las cuales, el $74 \%$ tiene entre 59 y 64 años y el $26 \%$ restante está entre los 65 años o más. Seguramente esta cifra subrepresenta la población real de lesbianas mayores de sesenta años que residen en esta ciudad. Más aún, como señala Rada Schultze (2016), este tipo de datos estadísticos «son tan sólo un recorte; una tipificación que poco nos dice sobre las características de las vejeces y de los procesos de envejecimiento que dieron como resultado esa vejez» (p. 83). Por lo tanto, resulta apremiante llevar a cabo investigaciones cuantitativas y cualitativas que indaguen sobre las vejeces lésbicas en Bogotá.

Estos silencios motivaron mi tesis de maestría en la cual analicé las relaciones sexoafectivas de lesbianas adultas mayores de Bogotá como una apuesta por reivindicar su derecho al amor y a la sexualidad en la vejez. Esta experiencia me llevó a comprender que hablar de relaciones sexoafectivas en la vejez lésbica también implica problematizar las condiciones socioeconómicas en las que viven, el tema de los cuidados y la soledad, la socialización y los vínculos relacionales. Esto, debido a que los arreglos amorosos que hacen las lesbianas adultas mayores dependen, entre otras razones, de sus situaciones materiales (Falquet, 2006).

En este artículo comparto algunos hallazgos de mi tesis. Particularmente, me pregunto cómo las lesbianas de Bogotá que hoy son adultas mayores gestionan sus relaciones sexoafectivas en esta etapa de sus vidas. Para dar respuesta a este interrogante me planteé como objetivo analizar la gestión de las relaciones sexoafectivas de lesbianas adultas mayores de Bogotá.

Esta investigación se enmarca en una perspectiva analítica que entreteje los planteamientos de la gerontología feminista y del curso de vida entendiendo la vejez como un proceso que se va construyendo en el transcurso de la vida (Hooyman, et al., 2002; Freixas, 2008; Blanco, 2011). Para Guerrero y Pineda (2010), «mirar a la vejez como experiencia vital cobra sentido, ya que permite 
tener acceso a su experiencia, nos introduce a su mundo y a la manera en la que se envejece» (p. 171). En ese sentido, examiné las trayectorias de vida de las lesbianas adultas mayores de Bogotá, buscando ofrecer algunas luces sobre aquellos elementos que no solo influyen en la manera en que construyen sus vínculos sexoafectivos en la vejez, sino que, además, repercuten en los significados y en la importancia atribuidos a ellos (Alves, 2010; Lacombe, 2016). Aunque dichas trayectorias están mediadas por una multiplicidad de dimensiones (raza, pertenencia étnica, clase social, edad, género, sexualidad, entre otros), en este artículo me centro en explorar el género, la sexualidad y la dimensión socioeconómica.

El artículo está dividido en cuatro secciones. En la primera, expongo la estrategia metodológica empleada para el desarrollo de esta investigación. En la segunda, presento el marco teórico-analítico que sustentará el análisis empírico. En la tercera, analizo cómo el género, la sexualidad y la clase social han incidido en las trayectorias sexoafectivas de las lesbianas adultas mayores entrevistadas. Finalmente, en la cuarta sección reflexiono sobre los significados y la importancia que adquieren los vínculos afectivos y sexuales en la vejez lésbica y cómo estos dependen, entre otros factores, de sus situaciones materiales.

\section{METODOLOGÍA}

Buscando contribuir a derrocar el mutismo que circunda a la vejez lésbica, entre finales de 2019 y mediados de 2020 me sumergí en la tarea de recopilar las historias de vida de ocho lesbianas mayores de sesenta años residentes en Bogotá. Recurrí a las historias de vida como una técnica cualitativa de recolección de datos en la medida en que estas me posibilitaban explorar sus trayectorias de vida (Pujadas, 1992; Puyana y Barreto, 1994; Bertaux, 1999; Ferraroti, 2007).

A través de la evocación de sus recuerdos, busqué comprender cómo estas mujeres han construido su propio lugar en el mundo. Asimismo, indagué sobre sus trayectorias sexoafectivas, sus vínculos relacionales y sus espacios de socialización, para analizar cómo dichas trayectorias han dado lugar a tipos de vejeces diferenciales repercutiendo en la manera en que hoy gestionan su emparejamiento y su sexualidad.

Aunque la información recopilada mediante las historias de vida constituye el eje central de esta investigación, siguiendo a Pujadas (1992), Puyana y Barreto (1994) y Albarracín (2012), acudí a la observación participante como una técnica complementaria. Lo anterior, en la medida en que me permitía realizar un acompañamiento a la cotidianidad de estas mujeres identificando sus rutinas, 
sus modos de socialización (vínculos relacionales y espacios de socialización) y la importancia que estos adquieren en su diario vivir, que me aportaron valiosos insumos para comprender con mayor detalle sus realidades.

Debo resaltar que investigar sobre las lesbianas adultas mayores suscitó grandes desafíos metodológicos y teóricos. Por un lado, me enfrenté a la falta de datos de tipo cualitativo o cuantitativo sobre lesbianas adultas mayores (Albarracín, 2012; Traies, 2015; Raphael y Cruikshank, 2015), lo cual complejizó el desarrollo de mi investigación. Por otro lado, las lesbianas adultas mayores no son una población de fácil acceso (Albarracín, 2012; Traies, 2016). En este sentido, para lograr un acercamiento con las participantes de esta investigación, la técnica de bola de nieve fue de gran utilidad, porque me permitió adentrarme en los vínculos relacionales de las lesbianas adultas mayores e ir estableciendo contactos paulatinos que hicieron posible el desarrollo de este estudio.

Una vez identificadas las posibles participantes, procedí a concertar los primeros encuentros para contarles acerca del objetivo de mi tesis y las motivaciones personales que me llevaron a querer reflexionar sobre la vejez lésbica en Bogotá. Estos primeros encuentros me hicieron confirmar lo que había revisado en la literatura: muchas lesbianas adultas mayores han vivido discretamente procurando pasar desapercibidas. Por ello, algunas de las mujeres con las que me iba a entrevistar — pese a que ya habíamos tenido un contacto telefónico previo- evitaron conversar conmigo en espacios cercanos a sus lugares de trabajo o de residencia. Por tal motivo, la mayoría de las entrevistas se llevaron a cabo en cafeterías o restaurantes. Solo en algunos casos puntuales se efectuaron en sus casas o lugares de trabajo. Claramente, yo comprendía sus prevenciones puesto que muchas de ellas nunca develaron su lesbianismo en su vecindario, ante su familia o con sus amistades. Sin embargo, no todas manifestaron estas prevenciones. Por lo contrario, algunas exhibieron un gran interés por encontrarse conmigo y por contarme sus anécdotas, porque — como señala Alves (2010) para esas mujeres esta investigación era la oportunidad perfecta para desahogarse y para hablar sobre aquello que antes no se habían atrevido a contar.

Con sus relatos, estas ocho mujeres pasaron de ser lo inimaginable a quedar en los registros de la historia, mostrando no solo cómo las lesbianas existimos en todas las cohortes etarias, sino que siempre hemos existido y que, de una $\mathrm{u}$ otra manera, hemos buscado estrategias para resistir y para sobrevivir en una sociedad heteronormativa que nos quiere silenciar y que quiere limitar nuestras posibilidades de amar. 


\section{LA VEJEZ COMO PROCESO: GERONTOLOGÍA FEMINISTA Y CURSO DE VIDA}

En nuestra sociedad, no es lo mismo envejecer siendo mujer que siendo hombre (Freixas, 1997; Ramos, 2018). En efecto, uno de los rasgos principales de la vejez es la heterogeneidad puesto que la trayectoria de vida de cada persona va moldeando determinados tipos de vejeces. En ese sentido, se llega a la vejez con un cúmulo de particularidades respecto del cuerpo, de la vivencia sexoafectiva, de las condiciones socioeconómicas y de los vínculos relacionales, entre otros (Freixas y Luque, 2009). Recientemente han surgido nuevas perspectivas teóricas críticas que cuestionan el enfoque gerontológico tradicional por su tendencia a homogeneizar a las personas adultas mayores en función de su edad (Ramos, 2018).

Más aún, como apunta Ramos (2018) «reconocer que ciertas condiciones negativas afectan por género a las mujeres a lo largo de sus vidas, no debe ocultar al mismo tiempo la diversidad que existe entre las propias mujeres mayores» (p. 77). En ese sentido, entender la categoría «mujer» de manera heterogénea y móvil $^{3}$ (Braidotti, 2000; Butler, 2007) resulta útil para evitar caer nuevamente en reduccionismos, resaltando las complejidades de envejecer, por ejemplo, siendo una mujer rural, indígena, en condición de discapacidad, transgénero, migrante o lesbiana.

De igual modo, entender la vejez como un proceso - es decir, como una etapa que se va construyendo a lo largo de la vida - contribuye a rescatar esa diversidad en las experiencias de envejecer (Hooyman et al., 2002; Freixas, 2008). Al respecto, la gerontología feminista y el curso de vida han realizado una gran aportación. Estas perspectivas abogan por la necesidad de indagar sobre las trayectorias de vida individuales al momento de llevar a cabo investigaciones sobre la vejez. Y es que, como señala Rada Schultze (2016), las trayectorias de vida de las personas están marcadas por una multiplicidad de dimensiones (etnia, clase, raza, género, sexualidad) que las condicionan, dando lugar a tipos de vejeces diferenciales.

3 Braidotti (2000) considera la categoría «mujer» desde una perspectiva móvil. En alabras de la autora, «el sujeto "mujer" no es una esencia monolítica definida de una vez y para siempre, sino que es más bien el sitio de un conjunto de experiencias múltiples, complejas y potencialmente contradictorias» (Braidotti, 2000, p. 30). Véanse también las discusiones de Butler (2007) respecto de la concepción de la categoría mujeres como un término común y estable. 
La gerontología feminista hace hincapié en las relaciones de poder y en las múltiples opresiones que se entrecruzan a lo largo del curso de vida de las mujeres (Hooyman et al., 2002). De acuerdo con estas autoras, «los análisis que incorporan una perspectiva feminista amplían nuestra comprensión del envejecimiento, yendo más allá de un enfoque singular de género a un enfoque más amplio en múltiples aspectos de la diversidad, incluidos los privilegios, la desigualdad y la interdependencia» (Hooyman et al., 2002, p. 3, traducción propia). Desde esta perspectiva, las desventajas acumulativas de las mujeres a lo largo de sus trayectorias de vida redundan en su inferior posición en el orden social en la vejez (Freixas, 2008).

Uno de los ámbitos de la vida de las mujeres en el que se ponen en evidencia estas desventajas acumulativas es el ámbito sexoafectivo (Freixas, 1997; Freixas, 2008; Ramos, 2018). En efecto, el amor y la sexualidad han sido objeto de censura, de prejuicios y, sobre todo, de control. Históricamente, a las mujeres se les ha impuesto con quiénes deben relacionarse y cómo. También se les ha enseñado que una característica de su «feminidad» es la pasividad, de tal suerte que aquellas que se revelan ante este orden y se apropian de su sexualidad y gestionan activamente su emparejamiento en cualquier etapa de su vida - pero particularmente en la vejez - tienden a soportar señalamientos (Freixas, Luque y Reina, 2010).

Simone de Beauvoir, en su libro La vejez, afirma que «dada la diferencia de su estatuto social, $[\ldots]$ la condición de objeto erótico desfavorece a las mujeres mayores» (Beauvoir, 2013, p. 397). Mientras que los hombres en la vejez pueden esperar ser atractivos y mantener una vida afectivo-sexual activa (González y González, 2005; Nóbrega, Silva, Souza y Fernandes, 2017), la sexualidad en las mujeres adultas mayores escandaliza y repugna (Beauvoir, 2013). Así pues, aquellas mujeres que desean continuar gestionando sus relaciones sexoafectivas en la vejez no solo se enfrentan a las críticas de su entorno; sino que, además, deben sortear la dificultad de encontrar una pareja (Freixas y Luque, 2009; Heaphy, 2009).

En relación con las lesbianas, históricamente su sexualidad ha sido objeto de censura. Por tal motivo, como señala Rich (1999) muchas lesbianas han tenido que ocultar sus relacionamientos sexoafectivos para evitar señalamientos, violencia física e, incluso, encarcelamientos. En el caso particular de las lesbianas que hoy tienen sesenta años y más, esta situación ha sido más acentuada por el contexto hostil en el que han transcurrido sus vidas. Esto ha incidido significativamente tanto en la forma en la que se han relacionado sexoafectivamente en el curso de sus vidas como en la manera en la que experimentan el amor y la sexualidad en la vejez. 
En este artículo retomo los planteamientos de la gerontología feminista y del curso de vida para comprender cómo el género y la sexualidad configuran las experiencias de envejecimiento de las lesbianas que hoy son adultas mayores en Bogotá. De acuerdo con Rada Schultze (2018):

El género y la sexualidad, son dimensiones importantes en las formas en las que se construye diferencialmente la vejez en el curso de la vida. El pertenecer a una minoría sexual históricamente estigmatizada impacta en las formas de envejecer y por consiguiente en el tipo, calidad y esperanza de vida [...] gran parte de estos «viejos y viejas» entrevistados, señalan que el haberse socializado bajo coyunturas disimiles a la actual, caracterizadas aquellas por regímenes opresivos que estigmatizaron las prácticas sexuales disidentes, los llevó a desarrollar sus vidas de maneras clandestinas, dejando su vida homosocial puertas adentro (p. 17).

Algunos autores han evidenciado que las lesbianas adultas mayores gestionan sus relacionamientos sexo-afectivos con mayores limitaciones puesto que se enfrentan a una triple dimensión de desigualdad (Rada Schultze, 2018). Por un lado, deben luchar contra los estereotipos edadistas y de género que desvalorizan e invisibilizan la sexualidad en mujeres adultas mayores (Beauvoir, 2013). Por el otro, deben hacer frente a la lesbofobia que persiste aún en esta sociedad aparentemente garantista de los derechos de las personas con orientaciones sexuales no heteronormativas.

La gerontología feminista, al tener como objetivo incidir en la vida de las mujeres adultas mayores, se propone cuestionar las nociones dominantes sobre este grupo históricamente marginalizado, promoviendo nuevas interpretaciones y representaciones sobre el envejecimiento de las mujeres que evidencien la complejidad de sus cursos de vida (Freixas, 2008). Al cuestionar las opresiones y desigualdades que experimentan las mujeres a lo largo de sus trayectorias de vida y sus consecuencias sobre la vejez, la gerontología feminista contribuye, por ejemplo, a romper los estigmas que coartan el derecho a vivir libremente la sexualidad y el amor en la vejez lésbica.

Bajo estas consideraciones, en este artículo sostengo que entender las experiencias de envejecimiento de las lesbianas adultas mayores de Bogotá a partir de la dimensión afectivo-sexual implica no solo tomar en cuenta sus realidades actuales, sino que, además, nos obliga a volver sobre sus pasados. Esto, en la medida en que contribuye a identificar aquellos aspectos de sus trayectorias que configuran la manera en la que estas mujeres construyen sus relaciones sexoafectivas en la vejez. En los siguientes apartados desarrollo estas ideas. 
Desempolvando el baúl de los recuerdos: relaciones sexoafectivas y trayectorias de vida

Las lesbianas adultas mayores que participaron en esta investigación constituyen un grupo heterogéneo. En efecto, sus trayectorias de vida individuales dieron lugar a experiencias de envejecimiento diferenciales. Estas distinciones se reflejan en las realidades que atraviesan cada una de ellas hoy en día. Al ser el ámbito sexoafectivo una parte inherente a sus realidades, la gestión de los relacionamientos de tipo sexual y afectivo en la vejez lésbica también se ve configurada por dichas trayectorias. En este apartado exploro algunas dimensiones de sus cursos de vida para comprender cómo estas inciden en la manera en que construyen sus relaciones sexoafectivas actualmente. Si bien enfatizo en las dimensiones de género y sexualidad, también exploro a grandes rasgos, otras dimensiones, por ejemplo, la dimensión socioeconómica.

Cada generación presencia acontecimientos históricos que moldean sus identidades y dan forma a los vínculos relacionales que construyen durante sus vidas (García, 2018). En el caso de las lesbianas que hoy son mayores de sesenta años, algunos estudios indican que «la experiencia del estigma continúa moldeando sus identidades y sus comportamientos» (Rosenfeld, 2005 citado por Traies, 2015, p. 37, traducción propia). Las historias de vida de las lesbianas adultas mayores con las que tuve la oportunidad de trabajar dan cuenta de cómo su devenir lesbiana ha influido en su socialización y, con ello, en la construcción de sus vínculos sexoafectivos.

Las trayectorias de vida de las lesbianas adultas mayores de Bogotá han estado fuertemente marcadas por el contexto en el que vivieron su infancia, su adolescencia y gran parte de su adultez. Por un lado, en aquel entonces (aunque persiste actualmente), como parte de su socialización de género, se les inculcaba la idea de que como mujeres debían ser pasivas, no debían causar problemas, debían estar más orientadas al hogar y a la familia y debían ser recatadas. Estos controles sociales informales (Osborne, 2008) incidieron, en cierta medida, en su mayor propensión a vivir una vida discreta, procurando pasar desapercibidas en su entorno.

Por otro lado, esta generación de lesbianas nacidas entre 1949 y 1960 fue testigo del estigma y el rechazo que han sufrido las personas que no son heterosexuales. Aunque ellas sostienen que desde sus experiencias no observaron que en aquel entonces en Bogotá el lesbianismo fuera objeto de tanta censura social y criminalización como en el caso de los gays, afirman que se socializaron bajo la 
idea de que los homosexuales eran enfermos, desviados e individuos peligrosos que atentaban contra la buena moral (Aparicio, 2009). Asimismo, las representaciones negativas sobre las lesbianas como «mujeres masculinizadas, malvadas o infelices» (Osborne, 2008, p. 46) ocasionaron que muchas de ellas evitaran ser identificadas como lesbianas y relacionadas con estos estereotipos. La conjunción de estos aspectos contribuyó a la invisibilización de sus existencias.

En ese sentido, la mayoría de las mujeres entrevistadas comentó que a lo largo de sus vidas han vivido su lesbianismo de manera discreta, como algo «privado», y que, por consiguiente, solo les concierne a ellas (y a sus parejas). $\mathrm{Y}$ es que, según sus testimonios, manifestar su lesbianismo implica asumir un «costo» mayor (discriminación, censura, distanciamiento familiar, entre otros) en comparación con el «costo» de vivir discretamente 4 . Este plus de la invisibilidad se justifica para ellas en cierta medida «por la paradoja que hace de la invisibilidad una suerte de aislamiento benigno al amparo del cual muchas lesbianas siguen su vida sin que se sepa la naturaleza real de sus relaciones» (Monleón, 2002 citada por Osborne, 2008, p. 47).

Si bien vivir discretamente ha sido una forma de resistencia para seguir gestionando sus vínculos sexoafectivos y para crear su identidad lesbiana - aunque sin usar necesariamente el término-- es importante recordar que Audre Lorde nos enseñó que las herramientas del amo nunca desmontan la casa del amo. Como ella afirma estas herramientas «quizás nos permitan obtener una victoria pasajera siguiendo sus reglas del juego. Pero nunca nos valdrán para efectuar un auténtico cambio» (Lorde 2003, 118). En sociedades excluyentes y discriminadoras, la discreción no puede ser considerada una «libre elección», como tampoco lo es la heterosexualidad. «Escoger» vivir ocultas posibilita que se sigan reproduciendo relaciones de opresión. Esto se esboza, por ejemplo, en el hecho de que las estrategias de discreción a las que han acudido estas mujeres también han supuesto su invisibilización histórica (Albarracín, 2008). La negación de la existencia de la vejez lésbica no es inofensiva ni casual. Precisamente, las vidas ocultas de las lesbianas, por el hecho mismo de mantenerse escondidas, han servido a algunos propósitos políticos heteronormativos (Rich, 1983) que han pretendido silenciar la existencia lesbiana con el fin de evitar su trascendencia (Albarracín, 2012).

Se refieren a los «costos» de estar desplegando estrategias para poder mantener su lesbianismo de manera discreta: cuidar cada detalle, evitar ser vistas públicamente con sus parejas o «disfrazar» la naturaleza real de sus relacionamientos con mujeres. 
Es el momento de soltar las herramientas del amo. Vivir ocultas a simple vista no debe seguir siendo la única «opción» aparente que tengan estas mujeres para seguir amando y existiendo. Es necesario que se resignifiquen sus existencias y resistencias. Para ello, generar investigaciones y espacios de debate que permitan empezar a visibilizar la vejez lésbica, en particular en nuestro contexto latinoamericano, constituye un buen punto de partida.

Ahora bien, pese a que la mayoría de las lesbianas adultas mayores entrevistadas manifestó ser discreta respecto de sus «gustos», algunas se distanciaron de sus familias. Para un porcentaje significativo de estas, haber migrado desde jóvenes de sus lugares de origen ${ }^{5}$ les posibilitó mantener cierta distancia de sus familias y atenuar ese miedo a ser descubiertas. Sin embargo, debieron seguir «guardando las apariencias» frente a sus otros vínculos relacionales (amigos y amigas, vecindario, colegas), lo que repercutió tanto en su manera de socializar con personas cercanas y con otras lesbianas como en la forma de gestionar sus relacionamientos sexoafectivos.

Asimismo, mencionan que, como consecuencia del estigma entre la década de los setenta y los noventa, los espacios de lesbosocialización eran escasos. Los testimonios de las entrevistadas evidencian que las opciones que tenían para socializar con otras lesbianas eran limitadas: «No había muchas opciones. Estaba el bar, la casa o la finca de alguna. Para los hombres había saunas, pero para las mujeres solo esos» (Liliana, 60 años).

Los bares lésbicos o bares de ambiente ${ }^{6}$ empezaron a aparecer en la escena de la rumba bogotana a principios de los años ochenta (Arcadia, 2017). Según recuerda Liliana «antes [de los años ochenta] solo había bares de maricas, pero no había bares de lesbianas. Y en los bares de maricas casi no dejaban entrar a las mujeres» (Liliana, sesenta años). Uno de los primeros bares lésbicos que surgió en Bogotá fue Bella Noche.

Según Patricia - una de las dueñas de Bella Noche-, este bar estaba ubicado en la calle 34, debajo de la avenida Caracas, en la localidad de Teusaquillo, al centro-Oriente de Bogotá. En ese tiempo «había muy poquiticos bares de ambiente, no era como ahora que hay por todas partes» (Patricia, 68 años). Y es que, durante la década de los ochenta, pese a que ya se había despenalizado la

Los lugares de origen de las entrevistadas son: Cali-Valle del Cauca, Guachetá-Cundinamarca, Ibagué-Tolima, Calarcá-Quindío, Pandi-Cundinamarca. Solo dos de ellas nacieron en Bogotá.

6 «Bar de ambiente» era un código empleado para referirse a los bares de lesbianas. Muchas lesbianas de la época emplearon este código para «identificarse, reconocerse y relacionarse, mientras camuflan su identidad en el entorno» (Albarracín, 2012, p. 78). 
homosexualidad en Colombia, ir a un bar lésbico «era un tabú: había que entrar a escondidas, que la gente no te viera, que nadie se enterara que era un bar de ambiente» (Patricia, 68 años). Ya para los años noventa Bogotá contaba con más «bares de ambiente». Sin embargo, «solo unos pocos eran exclusivamente lésbicos y un gran número de bares eran mixtos» (Cristina, 62 años).

Además de los bares, las entrevistadas relataron que para reunirse con amigas o parejas debían acudir al apartamento, la finca, la oficina o la casa de alguna de ellas: «yo tenía una oficina en Normandía ${ }^{7}[. .$.$] hacíamos almuerzo, rumbas,$ tomábamos. Pero solo la conocían las amigas, las que eran del cuento [...] era un sitio nuestro» (Cristina, 62 años). Estas posibilidades estaban sujetas, en gran medida, a los recursos sociales y económicos de los que dispusieran (Figari y Gemetro, 2009).

Dado que la socialización lésbica de estas mujeres en el curso de sus vidas estuvo marcada por diferencias de clase (Baker, 2016), aquellas que contaron con mayores recursos económicos pudieron procurarse más espacios para socializar y con ello, disponer de una amplia red relacional lésbica y vivir con cierta «libertad» su lesbianismo (Albarracín, 2008). Llegada la vejez, estas diferencias de clase se han hecho más notorias. Las que contaron con vínculos lésbicos amplios y con mayores espacios para interactuar han apreciado que con el paso del tiempo estos han tendido a reducirse. No obstante, siguen conservando la posibilidad de relacionarse con amigas o parejas potenciales, como se evidencia en el caso de Patricia, Liliana y Cristina.

Por su parte, aquellas que a lo largo de sus vidas no tuvieron acceso a espacios o vínculos relacionales lésbicos, o que procuraron evitar relacionarse frecuentemente con estos, en la actualidad evidencian mayores dificultades para encontrar pareja, como es el caso de Lilia y Leonor ${ }^{8}$. Y es que según cuentan, se vieron obligadas a mantenerse al margen del «mundo lésbico» porque percibían que involucrarse podía ponerlas en evidencia. Para mujeres como Matáfora ${ }^{9}$, este distanciamiento se relacionó más con el hecho de que para ella los bares y demás espacios lésbicos resultaban ser «ambientes muy pesados». Y aunque hoy en día tiene una relación con LuzPi, señala que, ante una posible ruptura, no contaría con los espacios ni con las redes lésbicas necesarias para retomar su vida amorosa.

Es un barrio de la localidad de Engativá, al noroccidente de Bogotá.

Pseudónimo.

Pseudónimo. 
Con respecto a sus trayectorias sexoafectivas, tres de las entrevistadas mencionaron que se casaron y tuvieron hijos en el marco de un matrimonio heterosexual. Una de ellas señaló que a sus veinte años se fue a vivir con el que después fue el padre de sus hijas, en parte, huyendo de la situación de carestía y violencia en la que vivía en casa de sus padres. Asimismo, como una manera «de huir de eso que estaba sintiendo por las mujeres» (Matáfora, 61 años). De este grupo de mujeres, una «inició su vida lésbica» a los 38 años, las otras, a los 50 y a los 65 años. Para esta última, haber empezado a salir con mujeres siendo adulta mayor le suscitó grandes desafíos, no solo porque considera que a su «avanzada edad» es difícil «conseguirse una mujer»; sino, porque, además, no dispone de redes relacionales lésbicas que le posibiliten estar en contacto con parejas potenciales.

Otras entrevistadas mencionaron que durante su juventud y adultez tuvieron varias relaciones sexoafectivas con mujeres, pero todas de corta duración. Solo algunas entablaron relaciones de pareja estables que duraron entre siete y doce años. Para estas, la viudez y la finalización de estas relaciones de larga duración constituyeron dos puntos de inflexión en sus trayectorias sexoafectivas, en especial porque dichos acontecimientos ocurrieron cuando estas habían sobrepasado los cincuenta años.

Con respecto a la viudez, Cristina mencionó que en 2015 murió Chela, su pareja, con quien llevaba aproximadamente siete años de relación. Esta pérdida tuvo grandes repercusiones en su vida sexoafectiva porque la sumió en situaciones de profunda depresión que incluso le han impedido entablar con éxito una nueva relación de pareja:

La muerte de Chela fue muy complicada para mí. Yo mi vida amorosa hasta el día de hoy no la he podido reorganizar. Los primeros días, meses y años fueron muy duros, porque yo trabajaba con ella todo el día: ella usaba mis chalecos, usaba mis cosas, usaba todo. Entonces, yo salía a trabajar, me ponía el chaleco y salía, me metía al carro y no podía trabajar, eso era chille, que chille y no podía trabajar. Eso era muy duro, y aún todavía hay días que me da durísimo (Cristina, 62 años).

Por su parte, otras perciben que la ruptura de una relación de larga duración — sobre todo cuando ellas ya «tienen sus años»—, limita la posibilidad de disponer de una relación estable en su vejez. Esto, a su vez, repercute en las situaciones de soledad en las que algunas de ellas viven hoy en día. Así lo expresa Liliana:

Terminar con ella fue difícil. Al principio la soledad fue muy complicada, sufrí mucho con eso, llegaba a la casa y me daba esa tristeza. Ahora me siento 
mejor, pero pues no sé, yo pienso que si ya a esta edad no tengo una pareja con la que haya creado una relación estable como han hecho mis amigas, creo que ya va a ser difícil, siempre la edad comienza a marcar. Entonces, yo ahora veo que, si no tengo una pareja, voy a seguir teniendo una vejez sola, porque yo no me llevo bien con mi familia (Liliana, 60 años).

Con respecto a la situación sexoafectiva actual de las entrevistadas, solo una de ellas estaba en una relación al momento de la investigación. La mayoría se encontraba en búsqueda de una pareja o mencionaba que no estaban cerradas a la posibilidad de «ennoviarse». Por su parte, dos de las entrevistadas sugirieron que no estaban interesadas en entablar una relación sexoafectiva en esta etapa de sus vidas y que preferían enfocarse en su familia (madre, sobrinas y sobrinos) o en su trabajo.

Por otro lado, durante el trabajo de campo pude apreciar que la situación material en la que se encuentran estas mujeres también incide en la manera en que construyen sus relaciones sexoafectivas en la vejez y en la importancia y los significados que les atribuyen (Falquet, 2006). Como he venido sosteniendo, esta situación material no es resultado exclusivo del momento actual en el que viven, sino que guarda estrecha relación con sus cursos de vida. Como se verá, las dimensiones de género y sexualidad también han ejercido gran influencia en la configuración de sus situaciones materiales en la vejez.

Pensemos, por ejemplo, que las trayectorias laborales definen el acceso a salud y pensión en la vejez. De acuerdo con Hooyman et al. (2002), el acceso al mercado laboral - y, por ende, a una pensión en la vejez- es uno de los aspectos en los que mayormente se evidencia la desigualdad y la opresión que experimentan las mujeres en el curso de vida. Para estas autoras, «el resultado de las oportunidades educativas limitadas, las barreras para la igualdad de empleo y los salarios bajos, es que las mujeres como grupo pasan sus vidas más pobres que los hombres, independientemente de su edad» (Hooyman et al., 2002, p. 7, traducción propia). Agregan que esta desigualdad es más sorprendente si se toman en cuenta los niveles de pobreza de las mujeres lesbianas, muchas de las cuales se enfrentan a una vida de bajos salarios y de discriminación laboral.

Con relación a la discriminación laboral, Adrienne Rich, en su ensayo sobre la heterosexualidad obligatoria y la existencia lesbiana, aborda la «sexualización de la mujer» en el ámbito laboral. Señala que, como consecuencia de los prejuicios heterosexistas, en el ámbito laboral una lesbiana no solo está obligada a aparentar «ser heterosexual sino una mujer heterosexual, en su vestido y en el desempeño del rol deferente y femenino exigido a las verdaderas mujeres» (Rich 
1999, p. 178). Esta situación fue asumida por algunas de las lesbianas adultas mayores entrevistadas, quienes comentaron que tuvieron que desplegar intrincadas estrategias de discreción ${ }^{10}$ para poder hacerse un espacio en el mercado laboral. Otras simplemente se revelaron ante dichas exigencias e imposiciones y optaron, ya sea por vivir su lesbianismo abiertamente en sus trabajos con la discriminación y la violencia que eso trajo consigo, o por tener sus propios negocios (in)formales que les permitieran ser independientes ${ }^{11}$.

En este orden de ideas, sus trayectorias laborales se vieron influidas no solo por el hecho de ser mujeres, sino también por ser lesbianas. Esto generó desigualdades en el acceso a una pensión en la vejez. Del total de las mujeres entrevistadas, solo tres disponen de una pensión en la actualidad. Las demás dependen de los ingresos diarios que les proveen sus negocios o de cualquier otra fuente de ingresos alternativa; por ejemplo, Leonor recibe una ayuda mensual de su nieto y un subsidio estatal.

Digo esto porque los testimonios de la mayoría de las lesbianas adultas mayores resaltan la importancia que tiene disponer de recursos económicos para la socialización y para la gestión sexoafectiva en la vejez. En efecto, aquellas que tienen una pensión o un ingreso fijo manifiestan que pueden frecuentar algunos espacios de socialización lésbica o permitirse sacar tiempo para sus «conquistas», mientras que aquellas que no cuentan con suficientes recursos tienen mayores limitaciones para su socialización y ven frustradas sus expectativas de conseguir pareja: «Este año iba a ir por allá [a un bar lésbico] porque uno allá si consigue viejas [mujeres] pero, no ve que pa'venirme a media noche por acá tan lejos es difícil, además, se necesita plata para eso» (Leonor, setenta años). Así, como señala Heaphy (2009), «la falta de recursos económicos disminuye los recursos sociales, limitando de esta forma las posibilidades íntimas y relacionales» (p. 133, traducción propia) de estas mujeres.

10 Entre las estrategias de discreción que mencionaron destacan: (i) «disfrazar» sus relaciones de pareja como otro tipo de vínculo relacional (hermanas, primas, tías, amigas); (ii) vestirse de manera «femenina», y (iii) acudir a espacios lésbicos procurando no ser vistas.

11 La mayoría de ellas se ha desempeñado en actividades relacionadas con el comercio. Una es propietaria de un local de artesanías al norte de Bogotá. Otra es gerente de su propia empresa dedicada a la importación y comercialización de productos industriales. Otra es vendedora informal en la plaza del barrio 20 de Julio al suroriente de Bogotá. Asimismo, una de las entrevistadas comercializa sus libros de poemas y algunos «cacharros», como ella les llama (aretes, bufandas, libros, mandalas, entre otros). 


\section{Significados e importancia de las relaciones sexoafectivas en la vejez lésbica}

Las lesbianas adultas mayores entrevistadas no atribuyen los mismos significados ni la misma importancia a las relaciones sexoafectivas en esta etapa de sus vidas. Estas diferencias están asociadas principalmente con sus situaciones materiales (Falquet, 2006). Para algunas, una relación sexoafectiva representa la posibilidad de disponer de compañía. Para otras, constituye un medio para procurarse los cuidados requeridos ante una enfermedad. Asimismo, otras expresaron que una pareja es un soporte para conseguir los recursos económicos necesarios para cubrir los gastos diarios. Sus relatos también dan cuenta de la importancia de disponer de un vínculo sexoafectivo para suplir sus necesidades de afecto y para dar continuidad a su sexualidad.

En primer lugar, algunas asociaron las relaciones sexoafectivas con la necesidad de compañía debido a que desde hace varios años viven solas. Para ellas, el tema de la soledad y el aislamiento es sentido como el «costo que se paga por ser lesbiana» (Wilkens, 2015, p. 90, traducción propia). En gran parte, porque debido a sus «gustos» por las mujeres se vieron en la necesidad de tomar distancia de sus familias (Heaphy, 2009; Traies, 2015). Algunas no mantienen contacto con estas desde hace décadas. Otras, esporádicamente hablan por teléfono con algún familiar, pero no se ven frecuentemente con estos. Solo unas cuantas mantienen una relación cercana con sus familias, principalmente, aquellas que tuvieron hijas e hijos.

De igual manera, se aprecia que con el paso de los años han ido perdiendo contacto con sus amigas de toda la vida, lo que contribuye a que hoy enfrenten marcadas situaciones de soledad. Así lo narra Patricia:

Yo tengo un grupo que estamos conectadas por WhatsApp. Pero por la distancia, ya se limita uno a estar como sola. Por ejemplo, yo me metí acá, acá ¿Quién me va a encontrar? ¿Quién me va a visitar? Nadie [...] yo por lo general estoy muy sola [...]. Mire, a veces no hago las cosas porque me siento sola, necesito una persona que me sostenga, que me alcance alguna cosa, que me haga conversación, que me acompañe. Yo siempre he dicho que el mundo es para dos y es de dos (Patricia, 68 años).

De la necesidad de compañía y de apoyo en las tareas diarias de su finca se deriva el deseo de Patricia de conseguir a la «persona indicada», como ella le llama. Y es que, reflexionando sobre su etapa actual de vida, Patricia afirma que, aunque ella se mantiene activa y vive tranquila en su casa, «sí quisiera encontrar a alguien que termine los días conmigo». 
En segundo lugar, los testimonios de algunas de las participantes de esta investigación también revelan que las relaciones sexoafectivas constituyen un medio para procurarse los cuidados necesarios ante la presencia de una enfermedad. Coincido con la idea de que no debe romantizarse a la familia como cuidadora, puesto que, si se observa en el entorno próximo, disponer de un vínculo familiar cercano no garantiza los cuidados en la vejez. Sin embargo, para Baker (2016) la importancia de los vínculos familiares en el caso de «las lesbianas mayores, radica en que la familia es a menudo una fuente de apoyo para las personas mayores. En la medida en que estas se distancien, pueden carecer del apoyo que los sistemas médicos y sociales suponen que existe» (Baker, 2016, p. 331, traducción propia).

Ante esta carencia de cuidados, algunas comentaron que contar con una pareja contribuye a «hacer la carga menos pesada» porque estas les brindan ese soporte que necesitan en su cotidianidad. El caso de Lilia es un gran ejemplo. Lilia es una mujer de 71 años que padece de diabetes, hipertensión y problemas renales desde hace varios años. Para ella sus parejas siempre han sido un soporte en el tema de los cuidados: la han acompañado a sus citas médicas, han estado pendiente de su dieta y han estado ahí cuando se ha sentido mal de salud. Aunque hoy en día Lilia no tiene pareja, señala que gracias a la estrecha relación que tiene con Miriam (una expareja), esta la acompaña en sus visitas al médico:

Cuando tengo una cita médica me acompaña Miriam, esta señora que le digo que fue mi pareja. Antes me acompañaba Belén, pero no ve que ella murió en 2017. Nosotras vivíamos juntas, pero ya no éramos nada. Ella me acompañaba en mis diligencias, me inyectaba mi insulina (Lilia, 71 años).

Se aprecia que en estos casos las exparejas también adquieren gran relevancia en los cuidados diarios que requieren algunas lesbianas en su vejez. Este tipo de relacionamientos se configuran bajo la noción de familia elegida. Estas familias elegidas, «proporcionan el contexto propicio para el apoyo emocional y práctico en la vida cotidiana» (Heaphy, 2009, p. 123, traducción propia) de estas mujeres. $\mathrm{Y}$ es que, como evidencian algunas de las entrevistas, las parejas actuales y las familias elegidas proveen no solo apoyo en los cuidados médicos, sino que, además, proporcionan compañía y soporte cotidiano.

Debo resaltar que, pese a la importancia atribuida a las relaciones sexoafectivas como una forma de procurarse cuidados ante una enfermedad, algunas comentan que no hay garantías de que efectivamente sus parejas se puedan encargar de ellas o viceversa. Esta es una de las preocupaciones de Matáfora, quien desde hace diez años tiene una relación con LuzPi: 
Pues a ratos me asusto porque no sé si ella se me llegara a enfermar. ¿Qué me dirían? ¿O qué harían? Claro que cuando ella se me enferma, yo soy quien la cuido, yo soy quien está pendiente de ella. Pero si fuera algo grave no sé qué me diría la familia, no sé, a veces más que por mí o por ella, pienso es que su familia si nos pueden separar (Matáfora, 61 años).

Y es que las parejas de lesbianas que no han «formalizado» su unión se enfrentan a la falta de reconocimiento de dicho vínculo y al cuestionamiento de su legitimidad, incluso en aquellas relaciones de larga duración de las que las familias han sido testigos. Dada esta situación, como expresa Matáfora, algunas se enfrentan al riesgo latente de no poder hacerse cargo de su pareja ante una discapacidad permanente, una enfermedad grave, e incluso, ante la muerte. Contrariamente, en el caso de parejas heterosexuales se espera que sea el esposo o la esposa quien asuma dicha responsabilidad ante un evento de este tipo.

Esta falta de reconocimiento y legitimidad de las relaciones de pareja lésbicas y la idea de que estas configuraciones relacionales no encajan bajo la noción tradicional de «familia» conlleva a situaciones de discriminación, de vulneración de sus derechos y de ejercicio de violencias, como relata Cristina:

Su familia no me dejó despedirme de ella en la clínica ni estar en su funeral [...]. No puede ser que personas que no entienden lo que es el amor entre dos mujeres hagan semejantes atrocidades. Yo no vi a Chela, la vi así de lejos, vi la foto. Todo esto fue angustioso, eran como esas ganas de querer ir y enfrentar a todo el mundo, pero también había una cosa que me detenía y era que ella no se merecía un espectáculo de esos. Pero muy duro el día siguiente, saber que no podía ir al sepelio y que además el día siguiente, era el cumpleaños de ella (Cristina, 62 años).

En tercer lugar, se aprecia que las relaciones sexoafectivas en la vejez lésbica son percibidas como un soporte para conseguir los recursos económicos necesarios para cubrir los gastos diarios. Para Matáfora, una relación de pareja se enmarca en la noción de compartir. Ese compartir incluye, entre otras cosas, los gastos diarios: «Para mí una relación de pareja significa que mi proyecto, es tu proyecto [...]. Es poder compartir gastos, hasta compartimos la camisa» (Matáfora, 61 años). Para ella, sus carestías económicas representan uno de sus principales motivos de preocupación en su día a día:

Tenemos dificultades por los recursos porque a veces llegan los recibos, que hay que pagar el arriendo y la plata no aparece. Entonces, ella al principio casi no me acompañaba a vender. Ella es muy buena para venderme como poeta. Ella tiene un buen discurso para venderme como poeta [...] Entonces, ella 
me ayuda en eso. Pero al principio no se veía vendiendo cacharros conmigo [aretes, mandalas, bufandas, entre otros], pero ha aprendido a venderlos. Entonces carga entre sus maletas también y yo cargo [...]. Eso es lo que nos ha dado de comer los últimos cuatro o cinco años (Matáfora, 61 años).

Retomando a Falquet (2006), «los “arreglos” amorosos y sexuales que estamos construyendo están íntimamente vinculados a la situación material en la que nos hallamos» (p. 55). Esta situación también se hace evidente en el relato de Matáfora. Como mencioné en apartados anteriores, dicha situación material depende a su vez de la manera en que se entretejen diversas dimensiones a lo largo del curso de su vida. Por ejemplo, cómo el ser lesbiana influyó en sus trayectorias laborales, y con ello, en la posibilidad de garantizarse - o no - el acceso a una pensión. Tales desventajas acumulativas con las que estas mujeres llegaron a la vejez no son al azar, sino que guardan relación con la forma en la que están ubicadas socioeconómicamente (Heaphy, 2009).

En cuarto lugar, los testimonios de las entrevistadas también reflejan que tener una relación de pareja es importante en la medida en que les permite suplir sus necesidades de afecto y dar continuidad a la vivencia de su sexualidad. Cristina, en sus relatos, manifiesta que su sexualidad sigue siendo un aspecto fundamental y significativo en esta etapa de su vida:

A esta edad eso sigue funcionando, eso está programado para que funcione hasta los ciento treinta años [...]. Eso funciona las veinticuatro horas, siete días a la semana. El deseo y la masturbación los vivo igual a cuando tenía treinta. Las relaciones que se tienen o el hecho de masturbarse desfogan un poco ese deseo, porque eso sigue vigente (Cristina, 62 años).

Para ella, disponer de una pareja resulta importante, entre otras razones, para poder «desfogar ese deseo». Por tal motivo, ella conserva intactas sus expectativas de entablar una relación sexoafectiva en su vejez. Además, porque como señala, salir con mujeres menores que ella «es muy bacano por la experiencia que uno aporta. Digamos, eso te hace sentir joven. ¿Cómo te digo? No tanto que te haga sentir joven, sino que te revitaliza» (Cristina, 62 años). Para Cristina, «mantenerse joven» a sus 62 años se refleja en la posibilidad de seguir disfrutando de su derecho a amar y a vivir activamente su sexualidad.

Pese a la importancia que la mayoría de las entrevistadas atribuyen a sus vínculos sexuales y afectivos, resaltan que a «esta edad» se enfrentan a mayores limitaciones para conseguir una pareja que en otras etapas de sus vidas. Al respecto Leonor menciona que: «¿Yo tan vieja ya qué? Yo vieja creo que ya no, yo no 
creo que haya una persona que se vaya a enamorar de mí. Además, no creo que haya personas iguales a mí, de la edad mía» (Leonor, 70 años). Como mencioné en el apartado anterior, muchas de las lesbianas que hoy son mayores de sesenta años han vivido discretamente sus relacionamientos sexoafectivos, lo que ha contribuido a su invisibilización. Esta «sensación de inexistencia» que ha sido una constante en sus vidas tiende a acentuarse en la vejez, como se aprecia en el comentario de Leonor.

Por su parte, si bien las lesbianas adultas mayores comparten los prejuicios y la desvalorización que circunda la sexualidad en mujeres mayores, los testimonios de algunas entrevistadas reflejan que «ser lesbiana es un agravante». Así lo mencionan Patricia y Cristina:

Ser lesbiana es un agravante. Una mujer heterosexual puede hacerlo con menos problemas, pero cuando una lesbiana de sesenta y más años quiere vivir su sexualidad y está en busca de una pareja, el tema es súper complicado. La presión que la sociedad ejerce es terrible, porque pareciera que prácticamente una está condenado a la muerte. Ya no hay nada que hacer. Entonces, las personas como que no ven una posibilidad pues ahí en una relación lésbica. Como si una no tuviera deseo, como si eso estuviera anulado. Las mujeres lesbianas de sesenta años no tienen casi posibilidades para tener una relación. La tratan a una como si fuera el pervertido que está dañando a las chicas con las que se mete (Cristina, 62 años).

Es que es una vida pesada, Annie [...]. Quizá tú ahoritica, por lo que estás muy joven, pero esta es una vida pesada. Ante la sociedad en Colombia y en Bogotá no han aceptado de frente [...] la misma sociedad rechaza. Por eso, [...] uno siendo así, en la vejez está muy solo (Patricia, 68 años).

Estos testimonios son el reflejo de la discriminación a la que se enfrentan muchas lesbianas adultas mayores en Bogotá, incluso aquellas que han procurado «pasar desapercibidas», manteniendo sus vidas sexoafectivas «puertas adentro». Como señala Cristina en su relato, la censura que experimenta al querer entablar una relación también frustra sus posibilidades de gestionar ese ámbito de su vida que es tan relevante para ella. Una mujer lesbiana de sesenta y más años que desea vivir su sexualidad activamente y está en busca de una pareja corre el riesgo de «incomodar», de «escandalizar» (Beauvoir, 2013) y de recibir calificativos despectivos (pervertida, por ejemplo), pasando por alto que el deseo, el placer y el amor no tienen edad (Almeida y Lourenço, 2007).

Ante la imposibilidad de encontrar una pareja, algunas entrevistadas mencionaron que optaban por la masturbación como una forma de gestionar su propio 
placer: «Yo acá disfruto mi soledad. Yo creo que todas nos deberíamos dar ese lujo de tener un espacio donde podamos andar desnudas, donde podamos masturbarnos» (Eugenia, 69 años). Freixas y Luque (2009) reconocen que hace falta mucha educación sexual que promueva el autoerotismo en mujeres, el cual ha sido objeto de censura, especialmente, para generación de mujeres que hoy son adultas mayores. Es por ello que insisten sobre la importancia de promover la masturbación como un recurso importante en cualquier etapa de la vida, y principalmente en la vejez.

\section{CONCLUSIONES}

A grandes rasgos he procurado exponer cómo el género y la sexualidad han influido en las experiencias de envejecimiento de las lesbianas de Bogotá que hoy son adultas mayores, en particular, en lo que respecta al ámbito sexoafectivo. La discriminación de la que han sido testigos a lo largo de sus vidas a razón de su lesbianismo configuró tanto su socialización como sus vidas amorosas y sexuales, incluso, incidieron en sus trayectorias laborales. Todo esto contribuyó tanto en la invisibilización de sus existencias (la cual se acentúa en la vejez) como en las precarias condiciones de vida que algunas enfrentan hoy en día.

Esta acumulación de desventajas a lo largo de sus trayectorias vitales redunda en la imposibilidad que tienen algunas de gestionar exitosamente sus relacionamientos sexoafectivos en la actualidad. Si en el curso de vida se enfrentaron a la falta de espacios de socialización lésbica, no contaron con los recursos para frecuentar estos espacios o se vieron en la obligación de mantenerse al margen para evitar ser «relacionadas con ese mundo»; hoy en día, estas limitaciones han tendido a acentuarse a razón de la edad que tienen, de su lesbianismo y de sus situaciones materiales.

Esta investigación muestra, además, que las lesbianas adultas mayores de Bogotá no gestionan su vida sexoafectiva guiadas exclusivamente por el «amor». En efecto, en el ejercicio de sus afectos y de sus sexualidades también intervienen otros elementos: por ejemplo, de si disponen de una pensión, de si están solas o en compañía, del grado de cercanía o distancia de sus familias, de su estado de salud, de su situación laboral actual, de la importancia que atribuyen a esta dimensión de sus vidas, de sus expectativas de vida y de la percepción que tienen de sí mismas. Además, estos deseos están influenciados por factores externos tales como la censura hacia su sexualidad, la falta de espacios de lesbosocialización pensados para adultas mayores y la discriminación a la que se enfrentan como lesbianas y como adultas mayores, entre otros. 
Para finalizar, quiero recalcar que resulta imperativo romper con las visiones homogeneizantes y heterosexistas presentes en el quehacer gerontológico convencional y propender a diseñar marcos analíticos que contribuyan a comprender las particularidades de las experiencias de las lesbianas adultas mayores $\mathrm{y}$, con ello, a visibilizar sus existencias.

La visibilización de la vejez lésbica se impone como un tema crucial para confrontar al régimen heterosexual que ha buscado normalizar la heterosexualidad; es decir, instaurarla como lo normal y como la norma (Yébenes Escardó, 2018) en detrimento de otras orientaciones sexuales e identidades de género no heteronormativas. La existencia de la vejez lésbica toma un significado particular frente a la estrategia histórica de oscurecimiento y ocultación de la existencia lésbica y frente a la discriminación y a la violencia a la que se han visto expuestas a lo largo de sus trayectorias vitales. No se debe ignorar que la lucha por el reconocimiento es una lucha por la existencia. Dicha lucha debe ser incluyente en términos etarios.

Además, quiero reiterar que, si seguimos ignorando las realidades de las lesbianas adultas mayores, estaríamos desconociendo que los mecanismos para superar la desigualdad por fuerza deben ser distintos y deben responder a las necesidades particulares de cada grupo (Gimeno, 2003). En ese sentido, abordar la vejez lésbica nos lleva a reflexionar, entre otros temas, sobre el alto costo del heterosexismo en la vida de esta generación de lesbianas, quienes, en su mayoría, fueron obligadas a vivir en absoluta discreción. También, nos lleva a poner sobre la mesa problemáticas como la falta de seguridad social en la vejez lésbica, la necesidad de agendas del movimiento de la disidencia sexual dedicadas exclusivamente a la generación de espacios alternativos para la socialización, para el acceso a salud, a oportunidades laborales o a un techo digno. Asimismo, sobre la necesidad de salarios universales para las lesbianas adultas mayores y sobre la importancia de reivindicar el derecho al amor y a la sexualidad en la vejez.

\section{REFERENCIAS}

Albarracín, M. (2008). Libreras y tebeos: las voces de las lesbianas mayores. En R. Platero (ed.), Lesbianas: discursos y representaciones (pp. 191-212). Barcelona: Melusina.

Albarracín, M. (2012). Identidad(es) lésbica(s) en el primer franquismo. En R. Osborne (ed.), Mujeres bajo sospecha. Memoria y sexualidad 1930-1980 (pp. 69-87). Madrid: Fundamentos. 
Almeida, T. y Lourenço, M. (2007). Envelhecimento, amor e sexualidade: ¿Utopia ou realidade? Revista Brasileira de Geriatria e Gerontologia, 10(1), 101-114. https://doi.org/10.1590/1809-9823.2007.10018

Alves, A. M. (2010). Envelhecimento, trajetórias e homossexualidade feminina. Horizontes antropológicos, 34, 213-233. https://doi.org/10.1590/ S0104-71832010000200010

Aparicio, J. (2009). Homosexualidades mediáticas: la emergencia de las «otras» sexualidades en los discursos periodísticos en Colombia. Nexus Comunicación, 6, $30-47$.

Averett, P., Pylant, J., Craft, K. y Ricks, I. (2018). I would do it again: Past and present experiences of older lesbians. Journal of Women \& Aging, 1-15. https://doi.org/1 $0.1080 / 08952841.2018 .1549435$

Baker, N. (2016). Lesbian Elders: Riding the Tsunami of Change. Women and Therapy, 39(3-4), 322-336. https://doi.org/10.1080/02703149.2016.1116865

Beauvoir, S. (2013). La vejez. Bogotá: Penguin Random House.

Bertaux, D. (1999). El enfoque biográfico: su validez metodológica, sus potencialidades. Preposiciones, 29, 1-23. https://doi.org/10.1080/02703149.2016.1116865

Blanco, M. (2011). El enfoque del curso de vida: orígenes y desarrollo. Revista Latinoamericana de Población, 5(8), 5-31. https://doi.org/10.31406/relap2011.v5.i1. n8.1

Braidotti, R. (2000). Sujetos nómades. Corporización y diferencia sexual en la teoría feminista contemporánea. Buenos Aires: Paidós.

Butler, J. (2007). Sujetos de sexo/género/deseo. En J. Butler (ed.), El género en disputa. El feminismo y la subversión de la identidad (pp. 45-99). Barcelona: Paidós.

Drumm, K. (2005). An examination of group work with old lesbians struggling with a lack of intimacy by using a record of service. Journal of Gerontological Social Work, 44(1-2), 25-52. https://doi.org/10.1300/J083v44n01_03

Eversmeyer, A. y Purcell, M. (2012). Without apology. Old lesbian life stories. Estados Unidos: Old Lesbian Oral Herstory Project.

Eversmeyer, A. y Purcell, M. (2009). A gift of age. Old lesbian life stories. Estados Unidos: Old Lesbian Oral Herstory Project.

Falquet, J. (2006). De la cama a la calle: perspectivas teóricas lésbico-feministas. Bogotá: Brecha Lésbica.

Fernández de Castro, A. (2021). Sin fecha de caducidad: Relaciones sexo-afectivas y modos de socialización de lesbianas adultas mayores de Bogotá (tesis de maestría). Facultad Latinoamericana de Ciencias Sociales - FLACSO, Ecuador. 
Ferraroti, F. (2007). Las historias de vida como método. Convergencia, Revista de Ciencias Sociales, 44, 15-40.

Figari, C. y Gemetro, F. (2009). Escritas en silencio. Mujeres que deseaban a otras mujeres en la Argentina del siglo XX. Sexualidad, Salud y Sociedad - Revista Latinoamericana, 3, 33-53.

Freixas, A. (1997). Envejecimiento y género: otras perspectivas necesarias. Anuario de Psicología, 73, 31-42.

Freixas, A. (2008). La vida de las mujeres mayores a la luz de la investigación gerontológica feminista. Anuario de Psicología, 39(1), 41-57.

Freixas, A. y Luque, B. (2009). El secreto mejor guardado: la sexualidad de las mujeres mayores. Política y Sociedad, 46(1-2), 191-203.

Freixas, A., Luque, B. y Reina, A. (2010). Secretos y silencios en torno a la sexualidad de mujeres mayores. Debate Feminista, 42, 35- 51. https://doi.org/10.22201/ cieg.2594066xe.2010.42.818

García, M. (2015). Vejez y homosexualidad (tesis doctoral). España: Universidad de Murcia.

García, M. (2018). Mayores y diversidad sexual: entre la visibilidad y el derecho a la indiferencia. Revista Prisma Social, 21, 123-148.

Garnets, L. y Peplau, L. (2006). Sexuality in the lives of aging lesbian and bisexual women. En D. Kimmel, T. Rose y D. Steven (eds.), Lesbian, gay, bisexual and transgender aging. Research and clinical perspectives (pp. 70-90). Nueva York: Columbia University Press. https://doi.org/10.7312/kimm13618-005

Gimeno, B. (2004). Vejez y orientación sexual. Recuperado de https://beatrizgimeno. files.wordpress.com/2009/09/informe-mayores-lgtb1.pdf

Gimeno, B. (2003). El amor que no osa decir su nombre...La invisibilidad de las lesbianas. Revista de la UNED, 21, 131-136.

González, J. y González, J. (2005). Estudio descriptivo de la sexualidad de personas mayores de 60 años en el Caribe colombiano. Revista Psicogente, 13, 17-27.

Gracia, J. (2011). Los derechos humanos y la posición social de las personas mayores LGBT. Un supuesto específico: los malos tratos. Papeles. El tiempo de los Derechos, 12, 1-48.

Guerrero, M., Pinedo, G. (2010). Mujeres envejecidas: experiencias de envejecimiento en México. Debate Feminista, 42, 166-184. https://doi.org/10.22201/ cieg.2594066xe.2010.42.826

Heaphy, B. (2009). Choice and its limits in older lesbian and gay narratives of relational life. Journal of GLBT Family Studies, 5(1-2), 119-138. https://doi. org/10.1080/15504280802595451 
Henning, C. (2017). Gerontologia lgbt: velhice, gênero, sexualidade e a constituição dos «idosos lgbt». Horizontes Antropológicos, 47, 283-323. https://doi.org/10.1590/ s0104-71832017000100010

Henning, C. y Debert, G. (2015). Velhice, gênero e sexualidade: revisando debates e apresentando tendencias contemporáneas. Revista MAIS 60. Estudos sobre Envelhecimento, 26(63), 8-31.

Hooyman, N., Browne, C., Ray, R. y Richardson, V. (2002). Feminist Gerontology and the Life Course. Gerontology \& Geriatrics Education, 22(4), 3-26. https://doi. org/10.1300/J021v22n04_02

Kehoe, M. (1989). Lesbian over 60 speak for themselves. Nueva York: The Haworth Press.

Lacombe, A. (2016). Negociaciones posibles: visibilidad, vejez y parentesco entre mujeres que mantienen relaciones sexo-afectivas con otras mujeres. Vibrant: Virtual Brazilian Anthropology, 13(1), 102-114. https://doi.org/10.1590/180943412016v13n1p102

Lima, A. J. (2020). Narrativas de histórias de vida de idosas lésbicas: Interseccionalidade entre velhice, gênero e sexualidade (tesis de Maestría). Universidade Federal do Ceará.

Lima, A. J. y Ferreira, A. (2021). Envelhecimiento de mulheres lésbicas e a experiencia da sexualidade. En S. Magalhaes y C. Nogueira (coords.), Envelhecimiento, género e sexualidades (pp. 223-240). Vila Nova de Famaliçao: Húmus.

Nóbrega, A. C. S., Silva, A.. S., Souza, J. F. y Fernades, F. F. P. (2017). A vovozinha de Perrault e Grimm: o imaginário na formação da sexualidade feminina na velhice. En K. D. Rosa, M. Caetano y P. A. Castro (orgs.), Género e sexualidade: interface e discursos (pp. 57-68). Campina Grande: Realize.

Osborne, R. (2008). Un espeso muro de silencio: de la relación entre una «identidad débil» y la invisibilización de las lesbianas en el espacio público. Asparkía, Investigación Feminista, 19, 39-55.

Paiva, A. (2007). Reserva e invisibilidade: a construção da homoconjugalidade numa perspectiva micropolítica. En M. Grossi, P. Uziel y L. Mello (eds.), Conjugalidades, parentalidades e identidades lésbicas, gays e travestis (pp. 23-46). Río de Janeiro: Garamond Ltda.

Parra, M. (2007). Los significados de ser mujer, lesbiana y envejecer: Vidas, discursos y realidades. (tesis de maestría). Chile: Universidad de Chile.

Pujadas, J. (1992). Cuadernos metodológicos 5. El método biográfico: el uso de las historias de vida en las ciencias sociales. Madrid: Centro de Investigaciones Sociológicas. 
Puyana, Y. y Barreto, J. (1994). La historia de vida: recurso en la investigación cualitativa. Reflexiones metodológicas. Maguaré, 10, 185-196.

Rada Schultze, F. (2016). El paradigma del curso de la vida y el método biográfico en la investigación social sobre envejecimiento. Revista de Investigación Interdisciplinaria en Métodos Experimentales, 1, 80-107.

Rada Schultze, F. (2018). La diversidad en el curso de la vida: cambios y continuidades en el envejecimiento de gays, lesbianas y trans. Buenos Aires: Teseo - Universidad de Buenos Aires (UBA).

Ramos, M. (2018). Estudio etnográfico sobre el envejecer de las mujeres mayores desde una perspectiva de género y de curso vital. Prisma Social, 21, 75-107.

Raphael, S. y Cruikshank, M. (2015). Introduction: special issue on old lesbians: exploring community, relationships, friendship, and well being. Journal of Lesbian Studies 19(1), 1-6. https://doi.org/10.1080/10894160.2015.972809

Rebellato, C., Azevedo, D. L., Miguel, D.F., Da Silva, R. (2021). Precisamos falar sobre velhices LGBTI+. En C. Rebellato, M. C. A. Gomes, M. R. F. Crenitte (orgs.). Introdução às velhices LGBTI+ (pp. 16-23). Río de Janeiro: SBGG-RJ- EternamenteSOU- ILC-B. https://doi.org/10.24328/2021/92908.00/01

Revista Arcadia (2017, 11 de agosto). La conquista del territorio. Revista Arcadia. Recuperado de www.revistaarcadia.com/contenidos-editoriales/especial-lgbti2017/ articulo/espacios-lgbti-en-bogota/65096

Rich, A. (1983). Sobre mentiras, secretos y silencios. Nueva York: Icaria.

Rich, A. (1999). La heterosexualidad obligatoria y la existencia lesbiana. En M. Navarro y C. Stimpson (eds.), Sexualidad, género y roles sexuales (pp. 159-211). México D. F.: FCE.

Secretaría Distrital de Integración Social (2019). Estudio cualitativo sobre la situación de derechos de las personas de los sectores sociales de lesbianas, gay, bisexuales, transgeneristas e intersexuales en envejecimiento y vejez del Distrito Capital.

Secretaría Distrital de Planeación (2019). Salud sexual y salud reproductiva de mujeres lesbianas en Bogotá: un acercamiento a sus derechos. Recuperado de http:// www.sdp.gov.co/sites/default/files/informe_final_investigacio_mujeres_lesbianas.pdf

Secretaría Distrital de Planeación (2019). Perspectiva de envejecimiento y vejez en personas lesbianas, gays, bisexuales, transgénero e intersexuales. Recuperado de http://sdp.gov.co/sites/default/files/perspectiva_envejecimiento_y_vejez.pdf

Tirado, E. (2018). Las trayectorias identitarias de personas mayores homosexuales residentes de la ciudad de Lima, Perú (tesis de licenciatura). Lima: Pontificia Universidad Católica del Perú. 
Traies, J. (2015). Old Lesbians in the UK: Community and friendship. Journal of Lesbian Studies, 19(1), 35-49. https://doi.org/ 10.1080/10894160.2015.959872

Traies, J. (2016). The live of older lesbian: Sexuality, identity and the life course. Londres: Palgrave Macmillan.

Westwood, S. (2013). Researching Older Lesbians: Problems and Partial Solutions. Journal of Lesbian Studies, 17(3-4), 380-392. https://doi.org/10.1080/1089416 0.2013 .773840

Wilkens, J. (2015). Loneliness and belongingness in older lesbians: The Role of Social Groups as Community. Journal of Lesbian Studies, 19(1), 90-101. https://doi. org/10.1080/10894160.2015.960295

Woody, I. (2014). Aging Out: A qualitative exploration of ageism and heterosexism among aging african american lesbians and gay men. Journal of Homosexuality, 61(1), 145-165. https://doi.org/10.1080/00918369.2013.835603

Woody, I. (2015). Lift every voice: voices of african-american lesbian elders. Journal of Lesbian Studies, 19(1), 50-58. https://doi.org/10.1080/10894160.2015.972755

Yébenes Escardó, Z. (2018). Heterosexualidad. En H. Moreno y E. Alcántata (eds.). Conceptos clave en los estudios de género, vol. 2 (pp. 123-135). México: CIEGUNAM.

\section{Entrevistas}

Cristina, comunicación personal, 29 de enero de 2020.

Cristina, comunicación personal, 18 de febrero de 2020.

Cristina, comunicación vía Skype, 4 de mayo de 2019.

Eugenia, comunicación personal, 24 de enero de 2020.

Eugenia, comunicación personal, 11 de febrero de 2020.

Leonor, comunicación personal, 12 de febrero de 2020.

Lilia, comunicación personal, 3 de febrero de 2020.

Lilia, comunicación personal, 11 de febrero de 2020.

Liliana, comunicación personal, 28 de enero de 2020.

Liliana, comunicación personal, 13 de febrero de 2020.

Matáfora, comunicación personal, 26 de febrero de 2020.

Patricia, comunicación personal, 4 de febrero de 2020.

Pilar, comunicación personal, 25 de enero de 2020.

Pilar, comunicación personal, 1 de febrero de 2020. 